\section{America Should Be Benign, if not Necessarily Hegemonic}

Kenneth N. Waltz's "Globalization and Governance" (PS, December 1999) makes a persuasive argument that the resilient state is far from withering away in the international system. This finding contrasts with the fashionable and influential thesis of globalization partisans like Thomas Friedman that the postCold War rise and impact of the "electronic herd" (really developed states' financial and informational elites) favoring "liberal" market capitalist countries have radically diminished the sovereign state in irreversible ways.

Professor Waltz's telling points include the fact that, so far, globalization and linked liberal democracy are mainly confined to northern latitudes; the interdependence of states measured in capital and trade flows does not exceed 1910 levels; and, while money markets are global, a few states continue to hold sway over who gets what when and how. Waltz and the globalists are both right in focusing on the U.S. as the world's politico-economic giant, a condition stirring American smugness and external resentment globalists blame on envy and culture-lag.

Holding as an analytical matter that the uneven distribution of capabilities is the key to understanding international politics, Waltz warned, apparently on ethical grounds, against the U.S. acting as a hegemon consistent with its unipolar status. The crucial difference between hegemonic status and hegemonic behavior is not stressed, as it should be. The closest Waltz came to depicting the U.S. as a hegemonic actor is in his welcome notice of U.S. spending running at Cold War levels. This is an implicit criticism of the outlays as social waste and a bigstick approach to world affairs, which is not required, except by bipartisan sensitivity to military-industry lobbying and implausible threats from "rogues" like North Korea.

Viewing the present condition of international politics as "unnatural," Waltz looked to the international system's presumed immutable rules whereby a bloc or a single state emerges to contain and reduce the hegemon's comparative influence. Yet, Waltz cited no evidence of such a checking balance emerging; and none seems to be even latently present. Waltz himself noted how "the winners are imitated by the losers, or they continue to lose."

The remedy for preventing the U.S. from abusing its power and wealth lies chiefly in domestic restraints, including a weak state theory in American history and culture, a braking condition Waltz did not cite. Waltz did mention that "the physical capabilities and political will" of the U.S. "cannot sustain world burdens indefinitely." Considering America's unimpressive percentile rating in financial aid to needy states, and also its highly selective interventionist responses to the 80-odd world conflicts and ecological-agrarian crises, one may seriously question whether the U.S. is even now carrying its fair share of responsibilities.

The U.S. is still distant from "benign hegemony," which Waltz judged to be a contradiction in terms. I do not, provided U.S. hegemony does not take an imperialist form. Globalists are right about new forces in world affairs. Waltz is right in pointing to hegemony's dark side. The latter is containable if the U.S. matches its self-image of compassion with appropriate deeds, redistributing more of its resources in an evenhanded way and working multilaterally to prevent or limit violent conflicts and human rights abuses beyond the Balkan and Arab-Israeli contexts.

Paul F. Power University of Cincinnati 


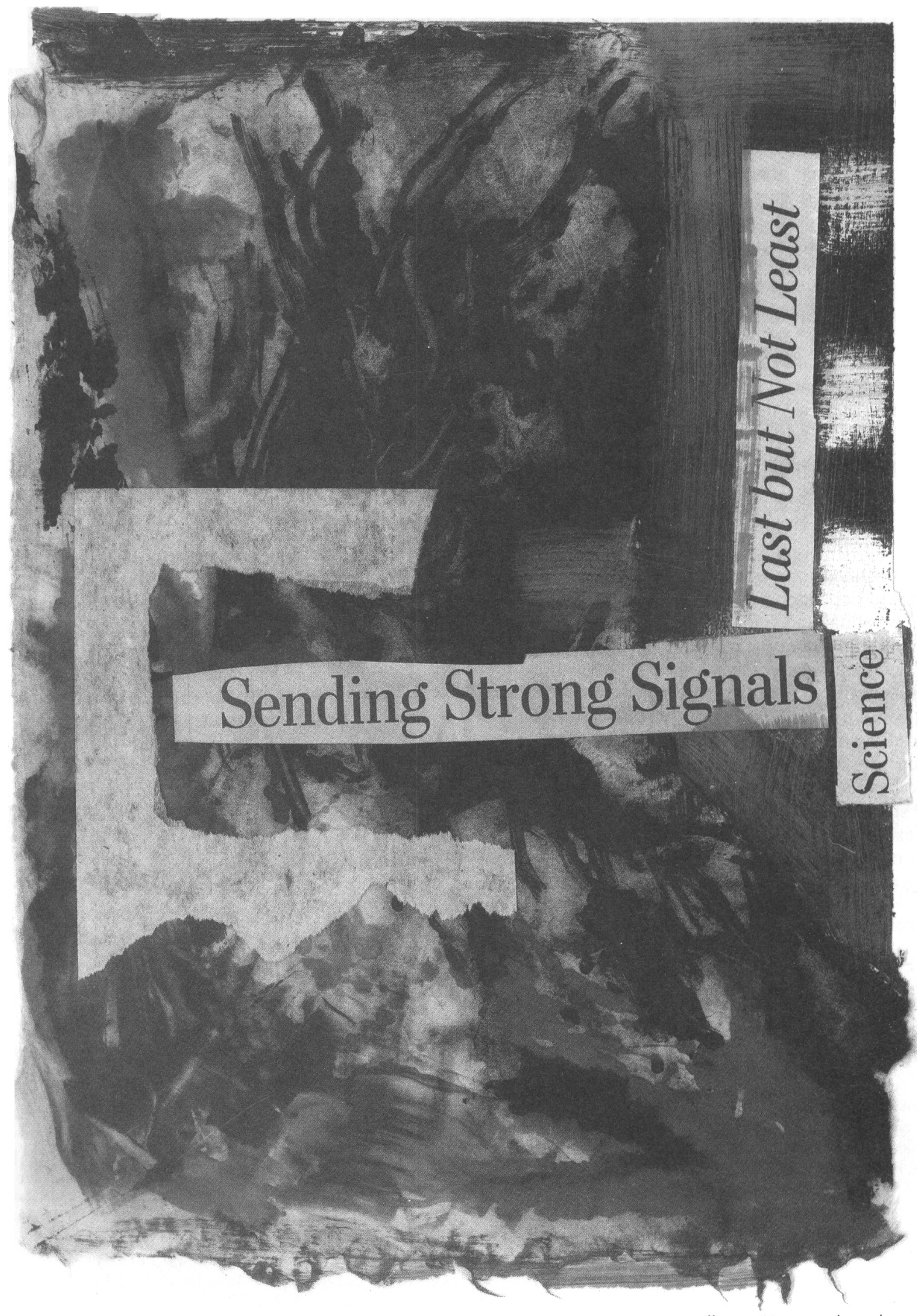

RJPH, Headlines \#1, mixed media 